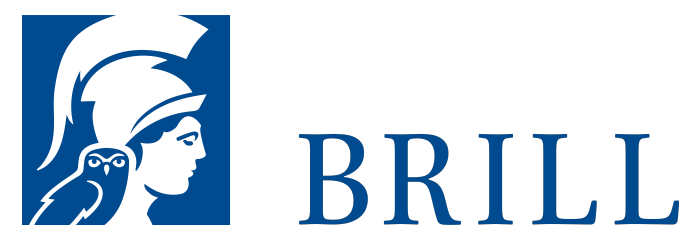

\title{
Hegemonie - multipolares System - Gleichgewicht
}

Internationale Beziehungen 1648/1659-1713/1714

Author: Klaus Malettke

Band 3 des HGIB behandelt eine Zeit, die weithin noch im Zeichen des bourbonischhabsburgischen Gegensatzes stand. Der Westfälische Frieden und der Pyrenäenfrieden ersetzten das von Habsburg-Spanien dominierte Staatensystem durch ein von Frankreich geführtes multipolares System. Nach den Friedensschlüssen von Nijmegen schien Ludwig XIV. der Verwirklichung der französischen Hegemonie sehr nahe gekommen zu sein. Ihr dauerhafter Ausbau scheiterte jedoch an der wachsenden Solidarität der durch Frankreich bedrohten Staaten, an dem sich unter Führung der Seemächte formierenden Widerstand im Zeichen des Gleichgewichtsprinzips (Tripel-Allianz, Ausbildung des französisch-englischen Gegensatzes) und an der Überforderung der wirtschaftlichfinanziellen Möglichkeiten Frankreichs. Hinzu kamen die politischen Veränderungen durch die »Glorious Revolution «, die sich im Dritten Nordischen Krieg vollzogen. Geprägt wurde diese Epoche auch durch den Abstieg bisheriger Großmächte (Spanien, Schweden, Osmanisches Reich) und den Aufstieg neuer Mächte wie das Russland Peters des Großen. Die österreichischen Habsburger konnten ihre Positionen nach dem Tiefpunkt von 1648 durch eine geschickte Reichspolitik und durch Erfolge gegen die Osmanen wieder stärken.

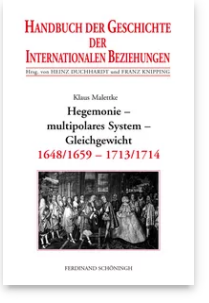

Pages: $\mathrm{XX}+583$

Seiten, $5 \mathrm{~s} / \mathrm{w}$

Abb.

Language:

German

Subjects:

General, History

Publisher: Brill |

Schöningh

Series:

Handbuch der

Geschichte der

internationalen

Beziehungen,

Volume: 3

E-Book (PDF)

Released online:

15 Jul 2019

ISBN: $978-3^{-}$

657-73723-9

List price

Hardback

Publication date: 10 Sep 2012

ISBN: 978-3-

506-73723-6

List price

USD \$180.00 
Klaus Malettke, Prof. Dr. phil., Dr. h.c., geb. 1936, war bis zu seiner Emeritierung Inhaber des Lehrstuhls für Neuere Geschichte mit dem Schwerpunkt Frühe Neuzeit an der Philipps-Universität Marburg. Er gilt als einer der wichtigsten wissenschaftlichen Vermittler zwischen Deutschland und Frankreich im späten 20. Jahrhundert. 2005 wurde er zum Offizier der französischen Ehrenlegion ernannt; 2007 wurde er mit dem Bundesverdienstkreuz 1. Klasse ausgezeichnet. Malettke ist assoziierter Professor und Ehrendoktor der Sorbonne in Paris.

For more information see brill.com

Order information: Order online at brill.com +44330 3330049 | customerservices@brill.com Submission information: brill.com/authors

Titles published by Brill | Fink, Brill | mentis or Brill | Schöningh: +49(o)71 5413279216 | brill@brocom.de 